\title{
O uso de metáforas como recurso didático no ensino do canto: diferentes abordagens
}

\section{Metaphors as a didactic resource in vocal pedagogy: different approaches}

\author{
Joana Mariz de Sousa ${ }^{1}$, Marta Assumpção de Andrada e Silva² ${ }^{2}$ Léslie Piccolotto Ferreira ${ }^{3}$
}

\begin{abstract}
RESUMO
Objetivo: Verificar se professores de canto de diferentes gêneros musicais utilizam expressões metafóricas ("imagens") como ferramenta didática para trabalhar a ressonância vocal, se existe correspondência fisiológica pretendida para cada metáfora empregada e os motivos para utilização de tal linguagem. Métodos: A amostra foi composta por 20 professores de canto, com experiência profissional mínima de cinco anos, atuantes em quatro abordagens do ensino de canto, sendo cinco professores por abordagem. Os professores responderam um questionário baseado em pesquisas já concluídas na área. As questões abordaram o histórico na docência de canto e a utilização ou não de metáforas. Aos professores que responderam afirmativamente foi solicitada a citação de três imagens correntemente utilizadas no ensino da ressonância bem como a explicação dos eventuais objetivos fisiológicos e musicais associados. As entrevistas foram gravadas em aparelho digital, transcritas na íntegra, analisadas e categorizadas. Resultados: Dos professores entrevistados, $90 \%$ utilizavam imagens no trabalho com ressonância por motivos didáticos técnicos e musicais; $88,8 \%$ dos professores que afirmaram utilizar tal linguagem e que disseram ter objetivos fisiológicos associados não os descreveram de forma objetiva ou não os distinguiram de objetivos musicais e proprioceptivos. Conclusão: A maioria dos professores pesquisados utiliza metáforas como ferramenta didática, por acreditar que elas estimulam a propriocepção e a musicalidade, e que a instrução por meio de linguagem fisiológica é muito complexa. Tal achado pode estar associado ao fato de que esses profissionais tendem a não separar o processo fisiológico de produção da voz do processo subjetivo da criação artística.
\end{abstract}

Descritores: Voz; Qualidade da voz; Treinamento da voz; Fonação; Propriocepção; Estética

\section{INTRODUÇÃO}

"Conduzir a voz para a frente”; "colocar a voz na máscara”; "cantar como num bocejo"; "dirigir a voz para cima, entre os olhos"; "não deixar a voz cair”. Essas expressões

Trabalho realizado no Curso de Especialização em Voz da Coordenadoria Geral de Especialização, Aperfeiçoamento e Extensão da Pontifícia Universidade Católica de São Paulo - PUC-SP - São Paulo (SP), Brasil.

(1) Especialista em Voz; Pós-graduanda (Mestrado) em Performance Vocal da Universidade Estadual Paulista "Julio de Mesquita Filho" - UNESP - São Paulo (SP), Brasil.

(2) Doutora, Professora Assistente dos cursos de graduação e pós-graduação em Fonoaudiologia e professora do Curso de Especialização em Voz da Coordenadoria Geral de Especialização, Aperfeiçoamento e Extensão da Pontifícia Universidade Católica de São Paulo - PUC-SP - São Paulo (SP), Brasil; Professora Adjunto do Curso de Fonoaudiologia da Faculdade de Ciências Médicas da Santa Casa de São Paulo - FCMSCSP - São Paulo (SP), Brasil. (3) Professora Titular do Departamento de Fundamentos da Fonoaudiologia e professora do Curso de Especialização em Voz da Coordenadoria Geral de Especialização, Aperfeiçoamento e Extensão da Pontifícia Universidade Católica de São Paulo - PUC-SP - São Paulo (SP), Brasil.

Endereço para correspondência: Joana Mariz de Sousa. R. Dr. José Almeida Camargo, 88, Jd. das Bandeiras, São Paulo (SP), Brasil, CEP: 05436-040. E-mail: joanamariz1@yahoo.com.br

Recebido em: 1/4/2009; Aceito em: 21/7/2009 metafóricas são exemplos de um jargão conhecido no meio musical como "imagens", e são utilizadas por professores de canto de abordagens técnicas e estilísticas as mais variadas em seu processo de ensino.

Por que o professor de canto utiliza tais metáforas como ferramenta? Qual será a correspondência objetiva entre uma determinada expressão metafórica e o resultado sonoro esperado por esse profissional? Que estratégias ele adota quando o aluno não compreende essa linguagem?

Estas perguntas foram a motivação principal para a elaboração do presente trabalho, que, a partir da análise de dados qualitativos, sugere uma reflexão sobre a questão do uso de imagens na didática do canto em meio à discussão geral sobre treinamento vocal.

Desde a época dos primeiros tratados, escritos a partir do século XV, até a atualidade, o conhecimento de canto vem sendo transmitido com base numa tradição geracional de professor para estudante por séculos. Nesse processo, um cantor que conseguiu ser bem-sucedido utilizando os ensinamentos de um cantor mais velho e experiente tende a transmitir sua experiência pessoal a cantores mais novos, que a retransmitirão a outros, e assim por diante ${ }^{(1,2)}$. 
As bases primordiais para que se dê esse processo de transmissão oral e empírica do conhecimento são os exemplos auditivos dados pelo professor de canto e uma terminologia eminentemente metafórica, fruto da tradição vocal em que este professor se formou ou de suas próprias sensações corporais e musicais. Trata-se de uma forma de ensino-aprendizagem de caráter artesanal, em que o ouvido, a intuição e a sensibilidade dos professores continuam sendo os principais critérios para avaliar o que é ou não bom na voz do aluno ${ }^{(3)}$.

Por outro lado, os constantes avanços da ciência da voz trouxeram novas informações sobre os fenômenos da voz cantada, confirmando algumas teorias intuitivas da tradição pedagógica do canto e mostrando que outras estão muito distantes da realidade fisiológica do aparelho fonador. À luz desse contexto, surge na segunda metade do século XX uma nova tendência de pedagogia vocal, profundamente engajada com as pesquisas científicas sobre voz cantada e fomentada por trabalhos interdisciplinares entre professores de canto e estudiosos da fisiologia, acústica e fonética da voz cantada ${ }^{(3,4)}$.

No entanto, o livre trânsito entre os estudos científicos da voz cantada e a prática do professor de canto encontra ainda alguns obstáculos. Em nome do rigor metodológico, a ciência vê-se obrigada a isolar da realidade os elementos que se propõe a estudar, a fim de obter resultados confiáveis e passíveis de generalização. $\mathrm{O}$ cantor em geral resiste ao contato com a perspectiva científica da voz, pois encontra dificuldade em utilizar esses resultados isolados em seu fazer artístico cotidiano, que abarca não somente o aspecto físicoacústico da voz, mas inúmeras questões pertinentes ao universo musical, marcado pela subjetividade e pela importância do processo criativo. Faz-se necessário, portanto, um esforço para a construção de pontes de comunicação entre os dois universos, para que um possa expandir seus conhecimentos a partir do diálogo com o outro ${ }^{(4)}$.

O problema da compreensão da terminologia utilizada pelo professor de canto não aparece somente quando há necessidade de trocas com áreas externas à música, mas também na comunicação com os alunos. O fato de a terminologia metafórica ser oriunda da experiência pessoal do professor ou de uma tradição vocal em que termos e exercícios são, muitas vezes, utilizados sem que se questione qual seu objetivo direto, pode levar à não compreensão do aluno da tarefa que deve realizar ${ }^{(5)}$.

O sucesso do ensino de canto depende enormemente da não-ambiguidade para o aluno dos significados dos termos usados no processo de estudo pelo professor ${ }^{(6)}$. Há quem considere que o uso de metáforas no ensino do canto pode induzir o mau funcionamento do aparelho fonador, porque as imagens funcionariam apenas como indicadores vagos de conceitos específicos, e que a pedagogia vocal poderia ter um grande avanço se elas fossem substituídas ou aumentadas por uma linguagem mais exata ${ }^{(7)}$.

No entanto, o ensino com expressões metafóricas tende a ser mais leve e divertido, enquanto o ensino sem elas pode ser árido e complexo, em especial para alunos iniciantes. Observase que um método de instrução ideal deveria equilibrar imagens e princípios científicos ${ }^{(5)}$.

Pesquisadores americanos apontam o problema de que nos Estados Unidos ainda não existem cursos de pedagogia vocal na área de música popular comercial americana, embora existam inúmeros cursos de graduação e pós-graduação em pedagogia vocal de canto erudito ${ }^{(8)}$. No Brasil, não se dispõe de qualquer tipo de curso de formação específica para o professor de canto ${ }^{(9)}$; nem mesmo material escrito em português sobre o assunto é facilmente encontrado. Segundo trabalho anterior, no país predomina a formação empírica e baseada em tentativas e erros, à custa da saúde e do tempo do aluno ${ }^{(10)}$.

O objetivo desta pesquisa foi verificar se professores de canto de diferentes gêneros musicais utilizam ou não imagens como ferramenta didática para trabalhar a ressonância vocal, assim como investigar qual a correspondência fisiológica pretendida para essas expressões metafóricas e os motivos para sua utilização no processo de ensino.

\section{MÉTODOS}

A presente pesquisa tem caráter qualitativo e descritivo, e foi aprovada pelo Comitê de Ética da Pontifícia Universidade Católica de São Paulo (PUC-SP), sob o número 122/2008. Todos os sujeitos assinaram o Termo de Consentimento Livre e Esclarecido antes de participar do estudo, permitindo o uso de seus depoimentos no todo ou em partes, sua publicação e apresentação em eventos de cunho científico.

\section{Seleção de sujeitos}

A amostra foi composta por 20 professores de canto de ambos os sexos, com idades e grau de formação musical variados. Foram critérios de inclusão a experiência profissional mínima de cinco anos na docência de canto e estar em exercício profissional no período da coleta de dados. A amostra foi construída em caráter proposital (purposeful sampling), buscando sujeitos que possuíssem a experiência e as informações necessárias ao desenvolvimento da pesquisa e que fossem casos típicos de professores de cada abordagem do canto, conforme a metodologia qualitativa de pesquisa ${ }^{(11)}$. Para este efeito a indicação dos profissionais envolvidos foi fornecida por cantores ou professores de canto de contato das autoras.

\section{Seleção de abordagens pedagógicas do canto}

A pesquisa avaliou as diferenças de enfoque da ressonância vocal em quatro tendências distintas de abordagem do ensino do canto, com as definições a seguir:

- Erudito: a definição ora adotada inclui o canto lírico, mais voltado à ópera, e o canto de câmara, dedicado à canção de arte erudita e à interpretação do repertório histórico ocidental;

- Popular brasileiro: o canto desenvolvido a partir do repertório típico da música popular brasileira, como, por exemplo, a Bossa Nova e o Samba;

- Canto Comercial Contemporâneo Americano (CCCA) (tradução livre de CCM - Contemporary Commercial Mu$\left.s i c^{(2-8)}\right)$ : inclui as técnicas norte-americanas de "belting" e "speech-level singing", e se aplica às técnicas notadamente 
associadas à música comercial americana, presentes no Brasil na música gospel e em outros segmentos da música pop, ou à técnica utilizada nas remontagens brasileiras de musicais da Broadway. A presença desta abordagem é recente no Brasil, mas já ocupa lugar de destaque no mercado de ensino de canto, por seu forte apelo comercial; - Holística: abordagem do canto desenvolvida a partir da concepção holística do ser humano, incluindo a abordagem antroposófica.

A escolha de tais abordagens de canto pretendeu garantir a formação de uma amostra suficientemente heterogênea para que surgissem diferenças significativas no método de ensino do canto em geral e do tópico ressonância em particular. $\mathrm{O}$ grupo de 20 participantes foi composto de cinco professores de canto para cada abordagem.

\section{Instrumento}

O instrumento de investigação foi um questionário de tipo aberto, elaborado especificamente para esta pesquisa, com base em trabalho que buscou aferir o significado da metáfora "voz na frente" em um grupo de professores e alunos de canto da Academia de Música da Estônia ${ }^{(6)}$. Esse questionário foi discutido na Conferência Mundial do Imaginário em Música (1999) e na VI Conferência de Percepção e Cognição Musical (2000). O questionário tem afinidades também com o instrumento utilizado em levantamento sobre a formação, a experiência e a terminologia de professores de $\mathrm{CCCA}^{(2-8)}$.

As questões para o presente trabalho tiveram como foco a formação geral do sujeito, a formação específica em música e canto, o tempo de experiência e o histórico na docência de canto, citação e explicação objetiva de três imagens correntemente utilizadas no processo de ensino da ressonância vocal e considerações sobre a importância do uso das metáforas. $\mathrm{O}$ questionário foi preparado também para inquirir sobre outras estratégias utilizadas para abordar a ressonância, inclusive para aqueles professores que não utilizassem a linguagem metafórica.

\section{Procedimentos de coleta e análise dos dados}

O instrumento de coleta de dados foi testado previamente em um piloto e em seguida recebeu ajustes e modificações principalmente nos enunciados das questões, de maneira a tornar-se auto-explicativo.

Os professores de canto foram informados de que se tratava de uma pesquisa na área de pedagogia vocal antes de concederem as entrevistas, mas não foi detalhado que o tópico principal da pesquisa seria a linguagem metafórica, a fim de evitar que a amostra fosse influenciada por essa informação.

$\mathrm{O}$ instrumento foi aplicado pessoalmente pela pesquisadora principal em entrevistas abertas. O registro dos depoimentos foi feito com aparelho de gravação de áudio tipo Mini Disc da marca Sony®, modelo MD Walkman MZ-R37, com microfone stereo da marca Sony®, modelo ECM-DS70P.

As respostas dos participantes, identificados pela letra $S$ acompanhada pelos números de 1 a 20 , foram transcritas na íntegra, lidas e relidas várias vezes pelas autoras.

\section{RESULTADOS}

Informações sobre idade, gênero, formação, tempo de atuação, abordagem adotada e perfil dos alunos atendidos foram organizadas no Quadro 1. Palavras e conceitos utilizados em comum pelos sujeitos foram categorizados em eixos temáticos ligados à pedagogia do canto e às especificidades de cada abordagem musical pesquisada, que possibilitaram a sistematização dos dados colhidos e sua exposição resumida nos Quadros 2, 3 e 4.

Em relação ao Quadro 1, observamos que os sujeitos entrevistados apresentaram faixa etária de 30-67 anos.

Com exceção de S14 e S15, com cinco e seis anos de experiência respectivamente, e de S18, que tem atuação em canto há seis anos, todos os sujeitos têm experiência superior a 13 anos na docência de canto, sendo a média geral de 19,6 anos (mínimo=5 anos; máximo=38 anos). Dos 20 professores entrevistados, $16(80 \%)$ atendem profissionais da voz, formados ou em formação, e os $20 \%$ (quatro) restantes atendem cantores amadores.

Nesse mesmo quadro verificamos que os professores de canto erudito são os mais velhos (média de 56,2 anos) e também acumulam mais tempo de experiência (25,4 anos). Em relação à formação foi possível perceber que, à exceção de $S 1$, que teve apenas formação técnica em piano, e S2 e S6, que têm nível superior incompleto, os demais professores da amostra (17 sujeitos - 85\%) possuem graduação acadêmica, mas apenas $11(55 \%)$ na área de música. Enquanto 80\% (16) dos professores da amostra de canto erudito e $60 \%$ dos da popular são graduados em música, apenas $40 \%$ (oito) possuem a mesma formação nas amostras denominadas CCCA e canto holístico.

Somente quatro professores da amostra (20\%) complementaram sua formação com pós-graduação em música, sendo que, destes, três (75\%) lecionam canto em cursos superiores da área, atuação profissional que exige este tipo de titulação. Por outro lado, oito (40\%) dos sujeitos buscaram complementar sua formação nas áreas de Fonoaudiologia (dois (40\%) dos professores de CCCA, um (20\%) dos de canto popular e um (20\%) dos de holística), Pedagogia, Terapia Ocupacional e terapias relacionadas à música em geral. Nessa última categoria encontram-se marcadamente os professores da abordagem holística (quatro - 80\%).

Os professores entrevistados observam que o ensino erudito de canto ainda representa a grande referência pedagógica da tradição musical ocidental, contra ou a favor da qual eles colocam suas posturas de ensino.

Essa interpretação é confirmada pelo fato de que 16 dos 20 professores entrevistados $(80 \%)$ estudaram ou estudam canto erudito. Os professores relataram que a busca pela formação técnica nesse gênero está relacionada à ausência de um método sistemático e de bases teóricas e técnicas em outras abordagens que não a erudita.

$\mathrm{Na}$ amostra de professores de canto popular brasileiro, quatro $(80 \%)$ dos entrevistados afirmaram ser autodidatas no estilo, tendo aprendido a cantar de forma diferente do canto erudito ao ouvir exemplos de cantores consagrados no Brasil, conversar com colegas, frequentar cursos de curta duração, experimentar vocalmente e buscar literatura estrangeira sobre 
Quadro 1. Caracterização da amostra em relação ao sexo, à idade, ao gênero de canto, a formação acadêmica e musical, ao tempo de experiência e ao tipo de atuação

\begin{tabular}{|c|c|c|c|c|c|c|c|}
\hline Sujeito & Gênero & Idade & Abordagem & Formação acadêmica & Formação musical & $\begin{array}{c}\text { Experiência } \\
\text { (anos) }\end{array}$ & Atuação \\
\hline S1 & $\mathrm{F}$ & 67 & Erudito & Não possui & $\begin{array}{l}\text { Piano, autodidata em } \\
\text { canto erudito }\end{array}$ & 22 & $\begin{array}{l}\text { Aulas particulares e } \\
\text { masterclasses }\end{array}$ \\
\hline S2 & M & 61 & Erudito & Incompleta em música & Canto erudito & 38 & $\begin{array}{l}\text { Aulas particulares, coro } \\
\text { profissional }\end{array}$ \\
\hline S3 & $\mathrm{F}$ & 56 & Erudito & $\begin{array}{l}\text { Graduação, mestrado, } \\
\text { doutorado e livre-docência } \\
\text { em canto }\end{array}$ & Canto erudito & 28 & $\begin{array}{l}\text { Aulas para graduação } \\
\text { em canto }\end{array}$ \\
\hline S4 & M & 53 & Erudito & $\begin{array}{l}\text { Música e letras, mestrado } \\
\text { em canto }\end{array}$ & Canto erudito & 26 & $\begin{array}{l}\text { Aulas particulares, } \\
\text { graduação em canto, } \\
\text { masterclasses }\end{array}$ \\
\hline S5 & M & 44 & Erudito & Música & Canto erudito & 13 & $\begin{array}{l}\text { Conservatório, coro } \\
\text { amador }\end{array}$ \\
\hline S6 & $\mathrm{F}$ & 46 & Popular & Incompleta em história & $\begin{array}{l}\text { Piano, coral, canto } \\
\text { erudito, método } \\
\text { antroposófico }\end{array}$ & 15 & $\begin{array}{l}\text { Conservatório, aulas } \\
\text { particulares }\end{array}$ \\
\hline S7 & $\mathrm{F}$ & 45 & Popular & Letras e educação musical & Canto erudito e popular & 17 & $\begin{array}{l}\text { Aulas particulares, coro } \\
\text { amador }\end{array}$ \\
\hline S8 & $\mathrm{F}$ & 44 & Popular & $\begin{array}{l}\text { Música e pós-graduação } \\
\text { em Fonoaudiologia }\end{array}$ & Canto erudito & 20 & $\begin{array}{l}\text { Aulas particulares, coro } \\
\text { amador }\end{array}$ \\
\hline S9 & $\mathrm{F}$ & 43 & Popular & $\begin{array}{l}\text { Graduação e mestrado } \\
\text { em música }\end{array}$ & $\begin{array}{l}\text { Canto erudito, popular } \\
\text { autodidata }\end{array}$ & 25 & $\begin{array}{l}\text { Graduação em canto, } \\
\text { aulas particulares }\end{array}$ \\
\hline S10 & $\mathrm{F}$ & 39 & Popular & Psicologia & $\begin{array}{l}\text { Canto popular, } \\
\text { continuada em erudito há } \\
16 \text { anos }\end{array}$ & 17 & $\begin{array}{l}\text { Aulas particulares, } \\
\text { workshops }\end{array}$ \\
\hline S11 & $M$ & 40 & CCCA & $\begin{array}{l}\text { Biologia, pós-graduação } \\
\text { em Fonoaudiologia }\end{array}$ & $\begin{array}{l}\text { Violão, canto erudito e } \\
\text { popular }\end{array}$ & 19 & $\begin{array}{l}\text { Escola de atores, aulas } \\
\text { particulares }\end{array}$ \\
\hline $\mathrm{S} 12$ & M & 38 & $\mathrm{CCCA}$ & $\begin{array}{l}\text { Música e pós-graduação } \\
\text { em Fonoaudiologia }\end{array}$ & Canto erudito & 20 & $\begin{array}{l}\text { Aulas particulares, } \\
\text { musicais e TV }\end{array}$ \\
\hline $\mathrm{S} 13$ & M & 38 & CCCA & $\begin{array}{l}\text { Graduação e mestrado } \\
\text { em música }\end{array}$ & Canto erudito & 20 & $\begin{array}{l}\text { Aulas particulares, } \\
\text { masterclasses }\end{array}$ \\
\hline $\mathrm{S} 14$ & $\mathrm{~F}$ & 32 & $\mathrm{CCCA}$ & Fisioterapia & $\mathrm{CCCA}$ & 5 & $\begin{array}{l}\text { Aulas particulares, } \\
\text { escola especializada em } \\
\text { teatro musical }\end{array}$ \\
\hline S15 & $\mathrm{F}$ & 30 & $\mathrm{CCCA}$ & Artes cênicas & CCCA & 6 & Aulas particulares \\
\hline $\mathrm{S} 16$ & $\mathrm{~F}$ & 61 & Holístico & $\begin{array}{l}\text { Música e pós-graduação } \\
\text { em musicoterapia }\end{array}$ & $\begin{array}{l}\text { Canto erudito, método } \\
\text { antroposófico }\end{array}$ & 20 & $\begin{array}{l}\text { Aulas particulares, } \\
\text { clínica, escola Waldorf }\end{array}$ \\
\hline S17 & M & 56 & Holístico & $\begin{array}{l}\text { Química e biologia, } \\
\text { pedagogia Waldorf e } \\
\text { cantoterapia }\end{array}$ & $\begin{array}{l}\text { Canto erudito, método } \\
\text { antroposófico }\end{array}$ & 30 & $\begin{array}{l}\text { Workshops e aulas } \\
\text { particulares pelo mundo }\end{array}$ \\
\hline S18 & $\mathrm{F}$ & 55 & Holístico & $\begin{array}{l}\text { Serviço social e } \\
\text { Fonoaudiologia }\end{array}$ & Método antroposófico & 6 & $\begin{array}{l}\text { Aulas particulares, } \\
\text { cursos }\end{array}$ \\
\hline S19 & $\mathrm{F}$ & 50 & Holístico & $\begin{array}{l}\text { Música, musicoterapia, } \\
\text { terapia ocupacional }\end{array}$ & $\begin{array}{l}\text { Piano, método } \\
\text { antroposófico }\end{array}$ & 30 & $\begin{array}{l}\text { Profissionais da } \\
\text { comunicação (grupo ou } \\
\text { não) }\end{array}$ \\
\hline $\mathrm{S} 20$ & $\mathrm{~F}$ & 39 & Holístico & Pedagogia e cantoterapia & $\begin{array}{l}\text { Canto erudito, método } \\
\text { antroposófico }\end{array}$ & 15 & $\begin{array}{l}\text { Crianças, professores, } \\
\text { sujeitos disfônicos }\end{array}$ \\
\hline
\end{tabular}

Legenda: $\mathrm{CCCA}=$ Canto Comercial Contemporâneo Americano 
voz ou de outras áreas do conhecimento, como a semiótica. Apenas um dos professores, S7, credita sua formação no estilo popular a de aulas de canto particulares específicas.

Houve predominância de mulheres na amostra (13 sujeitos - 65\%) (Quadro 1), sendo que no canto popular cinco (100\%) dos sujeitos eram do sexo feminino e na abordagem holística quatro (80\%), enquanto no erudito e no CCCA os homens foram maioria (três - 60\%). O grupo de 20 professores tem sua atuação principal em aulas ou atendimentos individuais, sendo que $15(75 \%)$ atuam também com grupos maiores de alunos, oito $(40 \%)$ pontualmente em workshops e cursos curtos, um $(5 \%)$ com aprendizes de atores, um $(5 \%)$ com profissionais da comunicação, um $(5 \%)$ com crianças, e quatro $(20 \%)$ regularmente como preparadores vocais de coros amadores ou profissionais.

Foi perguntado aos professores da amostra como eles abordam tecnicamente a questão da ressonância vocal. As respostas tiveram duas tendências básicas, conforme é possível observar no Quadro 2. Na primeira, os professores descreveram o tipo de exercícios que costumam adotar para despertar a qualidade vocal esperada no aluno; na segunda, os professores se preocuparam em definir o que é para eles ressonância, ou seja, a qualidade vocal ideal segundo sua concepção.

Na primeira tendência, as respostas destacam a importância de se considerar as características físicas e psicológicas do aluno antes de definir uma estratégia de abordagem da

Quadro 2. Estratégias técnicas utilizadas e conceitos relacionados à ressonância vocal descritos pelos participantes

\begin{tabular}{|c|c|c|c|}
\hline Sujeito & Abordagem & Estratégias & Conceitos \\
\hline S1 & Erudito & $\begin{array}{l}\text { Correção do apoio e precisão na articulação das } \\
\text { vogais. Imagens. }\end{array}$ & $\begin{array}{l}\text { A voz deve ser projetada nos ressonadores por } \\
\text { meio da respiração e do apoio. }\end{array}$ \\
\hline S2 & Erudito & Exemplo, imagens, movimentos. & As estratégias devem variar conforme o aluno. \\
\hline S3 & Erudito & Correção do apoio; imagens. & $\begin{array}{l}\text { Ressonância acontece por padrões } \\
\text { articulatórios, e muda conforme o estilo. }\end{array}$ \\
\hline S4 & Erudito & $\begin{array}{l}\text { Cada aluno pede estratégias e repertórios } \\
\text { diferentes; imagens. }\end{array}$ & $\begin{array}{l}\text { A base da ressonância é a respiração baixa e o } \\
\text { apoio. }\end{array}$ \\
\hline S5 & Erudito & Imagens e instruções musculares objetivas. & $\begin{array}{l}\text { Projeção vocal a partir da boa qualidade de } \\
\text { vibração da prega vocal, e não com excesso de } \\
\text { apoio. }\end{array}$ \\
\hline S6 & Popular & $\begin{array}{l}\text { Exercícios com vogais e fonemas mistos sem } \\
\text { forçar; imagens. }\end{array}$ & $\begin{array}{l}\text { A ressonância deve ser sentida fora do corpo, e } \\
\text { o aluno deve usar a imaginação para isso. }\end{array}$ \\
\hline S7 & Popular & Exercícios vocais (vocalises) e imagens. & A ressonância não deve ser padronizada. \\
\hline S8 & Popular & $\begin{array}{l}\text { Instruções musculares objetivas e explicações } \\
\text { sobre fisiologia. }\end{array}$ & $\begin{array}{l}\text { Não se deve impor um padrão de ressonância, } \\
\text { os alunos devem descobrir sua própria voz. }\end{array}$ \\
\hline S9 & Popular & $\begin{array}{l}\text { Exercícios feitos com atenção apurada do aluno } \\
\text { ao que está fazendo; imagens. }\end{array}$ & A ressonância não deve ser padronizada. \\
\hline S10 & Popular & $\begin{array}{l}\text { Buscar igualdade de timbres em toda a extensão } \\
\text { por meio de vocalises e imagens. }\end{array}$ & $\begin{array}{l}\text { Timbre deve variar com a interpretação de cada } \\
\text { música. }\end{array}$ \\
\hline $\mathrm{S} 11$ & $\mathrm{CCCA}$ & $\begin{array}{l}\text { Vocalises com ênfase na propriocepção; } \\
\text { imagens. }\end{array}$ & $\begin{array}{l}\text { A ressonância é o parâmetro vocal que define a } \\
\text { qualidade de uma voz e o estilo interpretado. }\end{array}$ \\
\hline S12 & CCCA & $\begin{array}{l}\text { Exercícios vocais de efeito previsível com } \\
\text { instruções musculares objetivas. }\end{array}$ & $\begin{array}{l}\text { Não há boa ressonância sem boa emissão. A } \\
\text { importância da ressonância é superestimada. }\end{array}$ \\
\hline S13 & $\mathrm{CCCA}$ & $\begin{array}{l}\text { Exercícios vocais com instruções musculares } \\
\text { objetivas e imagens. }\end{array}$ & $\begin{array}{l}\text { A ressonância muda conforme o estilo } \\
\text { interpretado. O belting demanda ressonância } \\
\text { orofaríngea e maior articulação do texto. }\end{array}$ \\
\hline S14 & $\mathrm{CCCA}$ & Vocalises para desenvolver o belting; imagens. & $\begin{array}{l}\text { Os alunos devem encontrar uma qualidade } \\
\text { metálica no som, de laringe alta e maior fluxo de } \\
\text { ar, típica do belting. }\end{array}$ \\
\hline S15 & CCCA & $\begin{array}{l}\text { Explicações sobre fisiologia; vocalises com } \\
\text { instruções musculares objetivas; imagens. }\end{array}$ & $\begin{array}{l}\text { A ressonância é um dos parâmetros vocais a } \\
\text { serem controlados pelo aluno. }\end{array}$ \\
\hline S16 & Holístico & $\begin{array}{l}\text { Vocalises com fonemas específicos, buscando } \\
\text { diferentes focos de ressonância (imagens). }\end{array}$ & $\begin{array}{l}\text { O som deve ser amplificado sem esforço } \\
\text { desnecessário. }\end{array}$ \\
\hline S17 & Holístico & $\begin{array}{l}\text { Descobrir focos de ressonância (imagens); } \\
\text { intensificar a escuta interna e externa. }\end{array}$ & $\begin{array}{l}\text { A ressonância é um fenômeno ligado à } \\
\text { espiritualidade. }\end{array}$ \\
\hline S18 & Holístico & $\begin{array}{l}\text { Utilizar o corpo todo como instrumento, } \\
\text { removendo aos poucos as tensões. }\end{array}$ & $\begin{array}{l}\text { A ressonância não é só técnica, mas um } \\
\text { fenômeno ligado à espiritualidade. }\end{array}$ \\
\hline S19 & Holístico & $\begin{array}{l}\text { Imagens com ênfase nas sensações } \\
\text { experimentadas pelo aluno. }\end{array}$ & $\begin{array}{l}\text { A busca pela ressonância é uma busca pelo } \\
\text { auto-conhecimento. }\end{array}$ \\
\hline S20 & Holístico & $\begin{array}{l}\text { Imagens; refinamento da percepção auditiva; } \\
\text { vocalises. }\end{array}$ & $\begin{array}{l}\text { Uma boa ressonância vem da fonação sem } \\
\text { esforço. }\end{array}$ \\
\hline
\end{tabular}

Legenda: $\mathrm{CCCA}$ = Canto Comercial Contemporâneo Americano 
ressonância, além de buscar saber em que estilo musical ele pretende cantar. As estratégias de trabalho citadas incluem: exercícios vocais variados; o uso de imagens; o uso de exemplos auditivos; exercícios de refinamento da percepção auditiva e da propriocepção; uso de movimentos corporais associados ao som; e uso de instruções fisiológicas objetivas com ou sem o auxílio de figuras de anatomia.

Numa outra tendência de pensamento, as respostas apontam a preocupação dos professores em definir conceitoschave para seu trabalho com a voz. Dos professores de canto erudito, três (60\%) citaram o uso do apoio respiratório como fundamental para se atingir uma boa ressonância, ressaltando a importância do fole no processo de produção da voz cantada; sete dos sujeitos, de todos os estilos (35\%) (S5=erudito; S6 e S8=popular brasileiro; S12=CCCA; S16, S18 e S20= holística), dão mais ênfase à qualidade da emissão, e ressaltam a necessidade de se produzir som sem esforço, com amplificação comandada pela vibração equilibrada das pregas vocais, fato que demonstra maior preocupação com a fonte sonora da voz.

S8 e S10, professoras de canto popular brasileiro, apontam que a questão do equilíbrio dos sub-registros modais de peito e de cabeça, por meio do bom funcionamento da muscula- tura intrínseca da laringe, deve ser a maior preocupação do professor de canto. Para elas, e também para S9, o professor não deve buscar padronizar a qualidade vocal do aluno, mas deixar que ele descubra sua própria personalidade vocal ou a voz adequada ao repertório, sendo papel do professor apenas ajudar a dissolver pontos de tensão excessiva.

Os professores da abordagem holística também dedicam atenção à fonação equilibrada, e consideram que a ressonância vocal é um terreno da espiritualidade, em que a escuta e a percepção vocal do indivíduo devem levar a níveis aprofundados de autoconhecimento.

Cinco (25\%) dos professores (três de CCCA, um de erudito e um de popular) entendem que é no âmbito das mudanças de ressonância, que para eles acontece no filtro do aparelho fonador, que se observam as diferenças entre os diversos estilos musicais, e, portanto, é onde o cantor que deseje transitar entre estes estilos deve procurar novas sonoridades.

Dos 20 professores entrevistados, apenas dois (10\%) disseram não utilizar imagens para ensinar a ressonância ou a qualidade vocal adequada a seus alunos. Ao responderem por que utilizam ou não o recurso das expressões metafóricas, seis tendências distintas de trabalho puderam ser explicitadas e encontram-se descritas no Quadro 3.

Quadro 3. Descrição e justificativa da utilização de imagens por parte dos entrevistados

\begin{tabular}{|c|c|c|c|}
\hline Usa & Justificativa & Sujeito & Abordagem \\
\hline Sim & $\begin{array}{l}\text { O canto é subjetivo e abstrato. O instrumento não é visível. As imagens têm um forte interesse } \\
\text { didático, pois são uma ferramenta que ajuda na comunicação com o aluno, tornando as instruções } \\
\text { do professor mais concretas. }\end{array}$ & $\begin{array}{l}\text { S1 } \\
\text { S7 } \\
\text { S9 } \\
\text { S10 } \\
\text { S11 }\end{array}$ & $\begin{array}{l}\text { Erudito } \\
\text { Popular } \\
\text { CCCA }\end{array}$ \\
\hline Sim & $\begin{array}{l}\text { O aprendizado do canto só acontece quando o aluno memoriza sensações proprioceptivas associadas } \\
\text { ao momento em que canta corretamente e melhora sua auto-percepção corporal. As imagens ajudam } \\
\text { a representar as sensações experimentadas pelo aluno, auxiliando-o a encontrar novamente o ajuste } \\
\text { que a causou. }\end{array}$ & $\begin{array}{l}\text { S1 } \\
\text { S2 } \\
\text { S4 }\end{array}$ & Erudito \\
\hline Sim & $\begin{array}{l}\text { As imagens ajudam o cantor a fazer a conexão entre a técnica vocal e a imaginação criativa exigida } \\
\text { na interpretação musical. O aprendizado do canto pertence à arte e não à ciência. As imagens ajudam } \\
\text { o cantor a sair do patamar excessivamente racional. }\end{array}$ & \begin{tabular}{|l} 
S6 \\
S7 \\
S14 \\
S16 \\
S17 \\
S18 \\
S19 \\
S20
\end{tabular} & $\begin{array}{l}\text { Popular } \\
\text { CCCA } \\
\text { Holístico }\end{array}$ \\
\hline Sim & $\begin{array}{l}\text { Explicações fisiológicas são muito complicadas para o aluno que ainda não conhece e não tem controle } \\
\text { de sua musculatura. Comunicar-se por imagens faz com que ele adote um determinado ajuste sem } \\
\text { que tenha que pensar em que partes do aparelho fonador está mexendo. Discutir com o aluno sobre } \\
\text { a musculatura pode distanciá-lo de realizar o som adequado. }\end{array}$ & $\begin{array}{l}\text { S3 } \\
\text { S7 } \\
\text { S9 }\end{array}$ & $\begin{array}{l}\text { Erudito } \\
\text { Popular }\end{array}$ \\
\hline Sim & $\begin{array}{l}\text { Imagens com objetivos musculares precisos são úteis para ajudar o aluno a conquistar sensações } \\
\text { proprioceptivas do canto e para levá-lo a compreender como sua musculatura funciona. Mas sempre } \\
\text { se deve explicar o ajuste muscular associado antes ou depois de sugerir a imagem ao aluno. }\end{array}$ & $\begin{array}{l}\text { S3 } \\
\text { S5 } \\
\text { S15 } \\
\text { S13 }\end{array}$ & $\begin{array}{l}\text { Erudito } \\
\text { CCCA }\end{array}$ \\
\hline Não & $\begin{array}{l}\text { As imagens levam o aluno a fabricar uma sonoridade que não é a sua natural. O aluno é levado a } \\
\text { realizar ajustes musculares sem explicações fisiológicas adequadas associadas, e pode adquirir } \\
\text { vícios, tensão e fadiga vocal, sempre dependendo do professor ou prendendo-se à sonoridade que } \\
\text { este lhe ensinou. }\end{array}$ & $\begin{array}{l}\text { S5 } \\
\text { S8 } \\
\text { S12 } \\
\text { S13 }\end{array}$ & $\begin{array}{l}\text { Erudito } \\
\text { CCCA } \\
\text { Popular }\end{array}$ \\
\hline
\end{tabular}

Legenda: $\mathrm{CCCA}=$ Canto Comercial Contemporâneo Americano 
A maioria dos professores que utilizam a linguagem metafórica concorda que é preciso adaptar seu repertório de imagens a cada aluno, e às vezes elaborar novas metáforas especiais para cada indivíduo, levando em conta suas características de personalidade. Seis (33,3\% dos que utilizam metáforas), de abordagens variadas, dizem elaborar as imagens que utilizam junto com o aluno, por meio de exemplos auditivos correspondentes à expressão sugerida e de conversas sobre adjetivos possíveis para a voz. Outros quatro $(22,2 \%)$ afirmam ter que "descobrir" qual a imagem mais adequada para conduzir o aluno à sonoridade preconizada pelo professor (um $(5,5 \%) \mathrm{de}$ canto erudito e três $(16,6 \%)$ de abordagem holística).

Um professor de canto erudito afirmou ser a favor do ensino por meio de explicações fisiológicas e objetivas, mas argumentou que o aluno iniciante não é capaz de compreender as informações necessárias, por serem demasiado técnicas, nem tem o controle muscular refinado exigido para lidar com essas informações. Em sua opinião, as imagens podem induzi-lo mais rapidamente a executar um determinado ajuste. Outros três professores (canto popular brasileiro, erudito e holístico) defendem que para os alunos com características mais racionais as expressões metafóricas não funcionam: eles precisam entender o processo que acontece em seu corpo para responder vocalmente.

$\mathrm{S} 2$ e S4 consideram que as preocupações com fisiologia e anatomia ultrapassam o campo de atuação do professor de canto. Para eles, esse profissional deveria atuar apenas no universo musical, desenvolver o potencial artístico dos alunos e ajudar a conectar suas sensações proprioceptivas à interpretação vocal.

Dentre os utilizadores de imagens, dois $(11,1 \%)$ (um sujeito de CCCA e um de erudito) concordam com os professores que não utilizam metáforas que, sem uma explicação fisiológica associada, a linguagem metafórica tende a dificultar a compreensão do aluno ou a fazê-lo imitar sonoridades pré-estabelecidas sem realmente apropriar-se vocalmente delas. Eles acreditam, porém, que as expressões metafóricas são uma ferramenta a mais na comunicação com o aluno, inclusive para auxiliá-lo na compreensão da fisiologia, e por isso tendem a utilizar uma linguagem mista de imagens e explicações fisiológicas. Para quatro (20\%) dos sujeitos entrevistados que questionam o uso de metáforas sem uma correspondência muscular objetiva e acessível ao aluno, o conhecimento aprofundado pelo professor de canto da fisiologia da voz cantada e dos fenômenos acústicos associados a ela é fundamental para o sucesso do treinamento vocal.

Foi pedido aos professores que fazem uso de imagens que descrevessem três exemplos comumente utilizados no ensino do tópico ressonância vocal. Em seguida, o questionário inquiriu sobre as possíveis correspondências musculares e, separadamente, sobre as correspondências musicais relacionadas a cada um dos exemplos citados.

A análise de dados mostrou que $16(88,8 \%)$ dos 18 professores que utilizam imagens não estabeleceram correspondências musculares precisas para as três metáforas citadas em seus depoimentos. Na maior parte das vezes eles descreveram os objetivos musculares de uma imagem sem distingui-los de seus objetivos musicais ou das sensações corporais do som associado a ela, sem se aperceber de que se tratava de tópicos distintos. Em outras, descreveram um objetivo muscular para uma ou duas imagens e, para a terceira, objetivos musicais. Foi comum também que o objetivo de uma imagem tivesse como explicação uma outra imagem.

Assim, ao explicar o objetivo da metáfora de "cantar como se estivesse numa catedral", um professor descreveu que seu propósito é o de "relaxar o aparelho fonador" (objetivo muscular), "trazer harmônicos" (objetivo acústico ou musical) e "escurecer a voz" (imagem).

Um outro professor citou que a correspondência muscular para a metáfora "cantar como o vôo de uma borboleta" seria dar "leveza à voz" (imagem). Outro sujeito apontou que a correspondência muscular para a metáfora "som na frente" seria "ressonância frontal", que é uma expressão praticamente sinônima àquela que teoricamente deveria explicar.

Apesar de ter sido notada uma relativa variedade de metáforas e uma multiplicidade de explicações fisiológicas e musicais possíveis para cada uma delas, observou-se a recorrência de algumas metáforas e de alguns temas. Dentre os exemplos, pode-se mencionar o bocejo, a voz "na frente", o "cantar como se fala", ou a valorização do "espaço". Tais metáforas foram em geral associadas à sonoridade vocal esperada do aluno e ao relaxamento das tensões excessivas do aparelho fonador e da musculatura circunvizinha.

O Quadro 4 apresenta algumas das imagens citadas para as quais os professores apresentaram descrições precisas das correspondências musculares pretendidas. No mesmo quadro, uma pequena amostra de outras imagens colhidas que nos pareceram ter objetivos semelhantes, aqui incluídas a fim de oferecer um pequeno panorama do material levantado na presente pesquisa. Cabe ressaltar que ultrapassa o escopo deste trabalho julgar se os objetivos musculares apresentados para as metáforas são os mais adequados ou não.

A maior parte dos professores considerou que as metáforas causam um efeito geral sobre a musicalidade do aluno, e que elas podem auxiliar no desenvolvimento dos seguintes tópicos musicais: impostação vocal, variações de timbre, extensão vocal, afinação, inteligibilidade e homogeneidade da voz, fraseado, dinâmica, flexibilidade da voz e intenção interpretativa.

Foi perguntado aos professores que estratégias eles costumam adotar quando o aluno não compreende suas instruções, sejam elas baseadas na fisiologia da voz ou em imagens. Apenas quatro $(20 \%)$ dos sujeitos afirmaram "quase nunca ter problemas" em serem compreendidos por seus alunos, fato que relacionam ao uso de exercícios com efeitos previsíveis e de uma linguagem objetiva e precisa.

Ainda assim, foi de concordância geral que o professor de canto deve ter um vasto repertório de estratégias para poder se adaptar às dificuldades de cada aluno. Dentre as propostas para melhorar a comunicação entre professor e aluno foram apontadas a alternância de vocalises (pequenas frases musicais usadas como exercícios de treinamento da voz); a prática de o professor cantar imitando a voz incorreta do aluno ou mostrando a correta; a de trocar a imagem sugerida por outra; a de abordar o mesmo tópico por outro ângulo (por exemplo, na abordagem da equalização da voz pela extensão, abordar a região aguda se o aluno encontrava dificuldades na grave); a de dar exercícios de refinamento auditivo (como a audição 
Quadro 4. Descrição das imagens e suas correspondências musculares segundo os professores de canto

\begin{tabular}{|c|c|}
\hline Imagem & Correspondência muscular descrita \\
\hline Bocejo (citado por quatro sujeitos - $20 \%$ ) & Elevar palato e abaixar parte posterior da língua. \\
\hline Sentir o perfume de uma flor (citado por dois sujeitos - $10 \%$ ) & $\begin{array}{l}\text { Proporcionar uma respiração tranquila, ativar a musculatura zigomática } \\
\text { e elevar o palato. }\end{array}$ \\
\hline $\begin{array}{l}\text { A ressonância da voz como uma lâmpada/um capacete/uma bolha de } \\
\text { sabão que envolve o cantor/cantar numa caverna /a voz como uma } \\
\text { gota de orvalho ou um sino }\end{array}$ & $\begin{array}{l}\text { Favorecer fonação equilibrada e sincrônica, sem pressão sub-glótica } \\
\text { excessiva. As imagens sugerem também sensações vibratórias na } \\
\text { cabeça e no corpo, além de uma maior atenção auditiva. }\end{array}$ \\
\hline A ressonância como um tubo de PVC na garganta & $\begin{array}{l}\text { Expansão faríngea, abaixamento da língua, alargamento dos pilares } \\
\text { faríngeos, levantamento do palato. }\end{array}$ \\
\hline $\begin{array}{l}\text { A voz como uma equipe de corredores de revezamento/a extensão } \\
\text { vocal como um armário de muitas gavetas }\end{array}$ & $\begin{array}{l}\text { Alternância da musculatura intrínseca da laringe (músculo tireo- } \\
\text { aritenóideo vai cedendo espaço à ação do músculo crico-tireódeo). A } \\
\text { imagem da estante pode ser também uma ferramenta para melhora } \\
\text { da afinação. }\end{array}$ \\
\hline Cantar como se fala/dizendo o texto/falar a vogal & $\begin{array}{l}\text { Buscar articulação semelhante à da fala durante o canto, evitando } \\
\text { rigidez e artificialismos. }\end{array}$ \\
\hline Vogais mais claras/mais escuras & Ajustes na faringe a na língua. \\
\hline $\begin{array}{l}\text { Inspirar abrindo espaço e cantar refazendo o caminho do ar (citado } \\
\text { por dois sujeitos - } 10 \% \text { )/susto lento/imaginar-se sugando um fio de } \\
\text { macarrão ao inspirar e manter a posição para o canto }\end{array}$ & Abaixar laringe, elevar palato, expandir faringe. \\
\hline Cúpula de uma igreja dentro da boca & Elevação do palato. \\
\hline Focar a voz & $\begin{array}{l}\text { Tensionar mais as pregas vocais (aumentar a adução), diminuindo o } \\
\text { escape de ar. }\end{array}$ \\
\hline Postura de admiração & Relaxamento da mandíbula e elevação do palato. \\
\hline Risada de bruxa, som frontal & Constrição faríngea, abertura lateral de boca. \\
\hline
\end{tabular}

de gravações da própria voz ou cantar de olhos fechados) ou de aumento da concentração; a de acrescentar movimentos corporais aos exercícios vocais; ou mesmo a de mudar o repertório estudado.

Seis $(30 \%)$ dos professores participantes relataram procurar não insistir demais num determinado tópico quando observam que o aluno não está conseguindo corresponder. Para S5 e S7 a auto-estima do aluno deve ser preservada, e a constante insistência num determinado defeito pode mesmo vir a amplificá-lo, por deixar o aluno angustiado e ansioso demais com relação a ele.

Parte da amostra (nove sujeitos - 45\%) relatou ser necessário também o respeito ao tempo de amadurecimento do aluno, e ao fato de que o processo de aprendizado do canto passa necessariamente por tentativas, erros e acertos. Para eles trata-se de um processo de condicionamento do corpo a determinados movimentos, que com o tempo se consolidam como controle ativo de um dado aspecto vocal. Outro fator citado por três (15\%) sujeitos é a necessidade de um canal de diálogo entre aluno e professor, para que o aluno tenha liberdade de expor suas dúvidas e o professor de conhecer seus pensamentos a respeito do aprendizado vocal.

Com relação às diferenças conceituais e técnicas entre as quatro abordagens escolhidas para a pesquisa, observou-se que certas tendências de trabalho, como o foco técnico na vibração equilibrada de pregas vocais, no equilíbrio dos sub-registros modais (peito e cabeça) ou na execução musical, aparecem de forma transversal entre os estilos, e não associadas a uma determinada abordagem ou escola.
No entanto foram encontrados conceitos predominantes particulares a cada abordagem: na erudita, a visão de que o apoio respiratório é o grande responsável pelos fenômenos acústicos da voz cantada projetada e a expectativa de que a voz se encaixe num ideal sonoro pré-estabelecido como correto; na de canto popular brasileiro, o uso da técnica vocal como ferramenta para a liberdade expressiva e a variedade de timbres, porém com controle das tensões excessivas; no CCCA, a concepção de que a técnica vocal pode fazer da voz um instrumento dinâmico e flexível, que possa se adaptar às diferentes exigências do mercado lançando mão das diversas mudanças de qualidade vocal possíveis; e, finalmente, na holística, a concepção de voz como elemento do espírito do sujeito, a ser integralmente descoberto por meio da técnica vocal, que potencializa o autoconhecimento e tem o alcance de um processo terapêutico.

\section{DISCUSSÃO}

A presente pesquisa investigou as estratégias pedagógicas e a utilização ou não de jargão metafórico (imagens) para o ensino do tópico ressonância vocal numa amostra de 20 professores de canto que trabalham com diferentes abordagens da voz, ativamente envolvidos na formação e na manutenção vocal de profissionais da voz. O fato de que a maioria desses profissionais tenha que lidar também com o ensino de técnica vocal para grupos maiores, sejam eles regulares ou pontuais, e não apenas com o universo da aula de canto particular processual, tende a conferir aos indivíduos da amostra uma gama 
mais diversificada de estratégias de ensino.

Com relação aos conceitos específicos encontrados em cada uma das quatro abordagens do canto escolhidas para a pesquisa, os depoimentos apresentaram coerência com a literatura específica apontada por $14(70 \%)$ dos professores da amostra como referências teóricas ${ }^{(7,12,13)}$.

Pesquisa anterior relata que os cantores populares tendem a começar suas carreiras apenas pela inclinação musical, sem o desenvolvimento de técnicas vocais associadas ${ }^{(14)}$. Tal informação parece conflitante com o fato de a totalidade da amostra de professores de estilos não-eruditos do presente trabalho ter desenvolvido aprendizado técnico formal. No entanto, percebe-se que a grande maioria deles $(73,3 \%)$ declarou ter recebido instrução formal na técnica erudita e ter procurado os gêneros não-eruditos de maneira autodidata. Esses professores têm o desafio de encontrar um método de ensino próprio que possa oferecer sonoridades vocais distintas da erudita, porém com eficiência técnica e respeito à saúde. Tal fato pode estar associado à crescente aproximação desse tipo de profissional da voz ao campo da Fonoaudiologia.

S8 (canto popular) e S12 (CCCA), pós-graduados em Fonoaudiologia, afirmam que o contato com a perspectiva científica da voz forneceu-lhes ferramentas para procurar maior liberdade expressiva a partir de suas bases no canto erudito, pois a compreensão da fisiologia vocal permitiu elaborar outros caminhos técnicos que não os do ensino tradicional de canto.

Com relação à abordagem da ressonância vocal, as respostas dos professores da amostra pesquisada mostram forte presença de uma não distinção de conceitos, apresentando elementos próprios da ressonância misturados ao conceito de timbre e ainda ao conceito de sub-registros vocais modais (peito, misto e cabeça). Isto parece se dever ao fato de que ainda não houve um esforço conjunto e interdisciplinar entre cantores e estudiosos da voz para encontrar uma terminologia comum, e, como fica claro ao observar o Quadro 2, nem mesmo entre os professores de canto existe um consenso.

Autores relatam que o termo ressonância tem realmente causado muita confusão no ensino de canto $^{(7,15)}$. O cantor tende a confundir a fonte sonora com a sensação que o som da voz cantada pode causar em diferentes partes da cabeça. Sem dúvida uma dada sensação corporal despertada pela voz possui um ajuste fonatório correlato, que causa a amplificação de determinadas frequências sonoras em detrimento de outras. Porém, isso não quer dizer, por exemplo, que tal sensação venha da circulação real do ar pelos ressonadores ou que o som esteja de fato "girando" pelas cavidades da cabeça antes de sair pela boca, como descreve uma das imagens mais comumente encontradas no ensino do canto.

As sensações vibratórias causadas pela voz poderiam ser a fonte da maior parte de explicações para o surgimento de metáforas como "cantar na máscara" ou "colocar a voz na testa, no pescoço ou no nariz". Para que essas sensações tivessem real utilização pedagógica e pudessem ser referência para a obtenção de uma impostação vocal saudável e eficiente, seria necessário que elas não variassem conforme o sujeito, a altura do som ou a mudança de vogais. Porém não é o que se observa na prática. Qualquer som suficientemente intenso quando propagado em um ambiente enclausurado causa vibrações nas paredes desse ambiente, seja ele saudável ou não, e essa seria a real causa para as vibrações no crânio, no pescoço e no peito dos cantores ${ }^{(16)}$.

Analisando o material colhido na presente pesquisa, percebe-se que o professor de canto busca em seus alunos algo que se aproxima mais de um trabalho com mudanças de qualidade vocal do que com adequação da voz do aluno a um timbre preconizado pelo professor. O timbre é a característica intrínseca de uma voz, quando comparada a outra em mesma intensidade e altura. Cada voz possui um conjunto de timbres, que varia conforme a região cantada (grave, média ou aguda) ${ }^{(17)}$. Já o conceito de qualidade vocal corresponde ao conjunto de ajustes de natureza fonatória (laríngeos) e articulatória (supralaríngeos) que caracterizam uma determinada produção sonora ${ }^{(18,19)}$, e parece encaixar-se perfeitamente como referência para descrever qual o objeto de trabalho cotidiano do professor de canto.

Foram verificados, nos dados colhidos, que os professores se preocuparam em definir seu próprio conceito de ressonância, ou seja, seu ideal de qualidade vocal, como um fator importante no estabelecimento de um diferencial de seu trabalho em relação ao de outros profissionais.

Destaca-se dentre os dados colhidos a importância que três (60\%) dos professores eruditos dão ao uso do apoio como grande responsável pela qualidade vocal ideal em contraposição à visão de oito (40\%) dos professores de todas as abordagens de que uma vibração de prega vocal equilibrada e sem esforço ou excesso de pressão sub-glótica seria o pré-requisito fundamental para um bom resultado vocal.

Pesquisadores relatam que há uma influência direta do volume pulmonar e da pressão sub-glótica sobre o modo de fonação, o que confirma que o apoio respiratório é um dos responsáveis pela qualidade da vibração fonatória ${ }^{(20)}$. Por outro lado, a literatura científica sobre voz cantada tem dado bastante destaque para a atuação equilibrada da musculatura intrínseca da laringe, desde a obtenção de um ataque vocal suave e a manutenção do sopro sem hiper ou hipofunção, até a valorização da atuação coordenada dos músculos tireoaritenóideo e crico-tireóideo ${ }^{(21)}$.

Pedagogos do canto influenciados pelas pesquisas científicas destacam em seus manuais a importância do bom funcionamento dessa musculatura, e descrevem o alto custo à saúde vocal que o excesso de apoio pode causar ${ }^{(7)}$. O contato com essa vertente da literatura sobre voz cantada certamente influenciou os sujeitos da presente pesquisa em sua escolha do bom funcionamento do mecanismo intrínseco da laringe como destaque de suas abordagens técnicas.

A elevação do véu palatino, citada por $11(55 \%)$ dos professores como fundamental para uma boa ressonância, encontra, na literatura, informações díspares. Pesquisas da década de 50 evidenciam que o véu palatino não se eleva completamente durante o canto erudito, e que acontece um acoplamento entre orofaringe e nasofaringe fundamental para a ressonância típica do estilo. Nesse caso, o uso da imagem do bocejo, citada por quatro sujeitos, seria contraproducente para o canto, por induzir elevação excessiva do palato mole ${ }^{(7)}$. No entanto, pesquisa mais recente, da década de 90 , revela que há elevação acentuada do palato no canto erudito, fato esse 
que contribui inclusive para que haja sacrifício dos fonemas nasais na região aguda ${ }^{(15)}$.

A imagem de "falar o texto ou a vogal enquanto se canta" foi citada por três (60\%) sujeitos da amostra de canto erudito, por apresentar a vantagem de aliviar a rigidez da articulação do texto. A literatura considera, porém, que a frequência fundamental de diversas notas mais agudas encontra-se em frequência superior à do primeiro formante de algumas vogais cantadas, comprometendo bastante a inteligibilidade nesses casos. Ao se acrescentar a isso que as cantoras de voz aguda costumam sintonizar seu primeiro formante à frequência fundamental, tornando-o artificialmente mais agudo para ganhar maior audibilidade, a questão da associação entre fala e canto na abordagem erudita torna-se ainda mais distante ${ }^{(22)}$.

Chamou a atenção ainda o fato de que a maioria das metáforas utilizadas por professores de todas as abordagens e suas respectivas explicações parece levar a ajustes mais típicos do canto erudito, à exceção de algumas específicas para belting (técnica que trabalha com quociente de fechamento glótico acentuado, predominância da sonoridade do sub-registro modal de peito e constrição faríngea ${ }^{(2)}$ ). Parece provável que isso se deva ao fato de que grande parte dos professores tenha sido instruída na técnica erudita, e ainda não tenha elaborado um repertório de imagens específicas para seu estilo. Pode ser também que alguns desses professores acreditem que a diferença de sonoridade dos estilos surge apenas por fatores de interpretação, o que é um julgamento incorreto ${ }^{(2,8,23)}$.

Ficou evidente que a maior parte dos professores pesquisados não têm a preocupação em relacionar sua prática cotidiana com o jargão metafórico a ajustes bem definidos do trato vocal. Exceção feita a dois sujeitos, que não por acaso são os mesmos que relataram achar benéfico o uso de imagens desde que com objetivos precisos e bem referenciados na fisiologia da voz. A tendência maior dos participantes é a de manter conjugados e inseparáveis a prática musical e o desenvolvimento da voz por meio de sensações proprioceptivas, essas sim bastante valorizadas.

No entanto, $100 \%$ dos professores que afirmam utilizar a linguagem metafórica afirmam que existem objetivos musculares a serem alcançados pelo aluno que tem contato com as imagens citadas. Ao confrontar este fato com a recorrência de determinadas imagens ou de tipos de metáforas semelhantes nos depoimentos colhidos, infere-se que existem ajustes fonatórios específicos a serem realizados pelos alunos de canto, mesmo que os professores não estejam preocupados em relacionar cada uma de suas metáforas à fisiologia da voz ou conscientes desta relação.

Os cantores em geral canalizam suas preocupações ao impacto final de sua performance e dão pouca atenção aos fatores físio-acústicos da produção do som. No entanto, qualquer abordagem da técnica vocal exige que se estabeleçam relações com o caráter físico do aparelho fonador, em níveis mais metafóricos ou precisos, mais genéricos ou específicos. As diferenças de estética vocal entre os diversos estilos musicais (por exemplo, entre a voz operística, a voz típica da Bossa Nova e a voz do canto belting) acontecem também por formas distintas de utilizar fisicamente o aparato pneumofonoarticulatório. O sucesso de qualquer abordagem da técnica vocal depende de sua chegada ao resultado estético planejado com o menor custo (de tempo e de saúde vocal) possível para o cantor ${ }^{(7)}$.

Embora a análise de dados tenha trazido à tona uma série de imprecisões conceituais nos professores pesquisados no que diz respeito ao domínio da linguagem e do referencial teórico científico sobre a voz, é de conhecimento geral que as expressões metafóricas são parte fundamental do universo artístico-musical da voz. Pedagogias inteiramente baseadas na imagem têm formado excelentes cantores desde séculos antes do surgimento das questões expostas nesta pesquisa. Ademais, o conhecimento dos fatos científicos da voz cantada não garante o melhor desempenho musical de um aluno de canto ${ }^{(4)}$.

Como referido anteriormente, o jargão metafórico parece ter sua origem na tentativa de descrição das sensações corporais positivas experimentadas pelo cantor ${ }^{(16)}$, e pode nesse sentido servir como guia a um aluno de canto, desde que este consiga interpretá-lo e conquistar suas próprias sensações. Para vários dos professores entrevistados, as imagens estabelecem uma conexão necessária entre a técnica vocal e a imaginação e a criatividade, que são responsáveis por transformar uma sucessão de sons sem sentido em ideias musicais expressivas.

Correntes da Psicopedagogia defendem que a capacidade de aprendizado é potencializada quando se incluem elementos do universo inconsciente ao processo racional de aprendiza$\mathrm{gem}^{(24)}$. Autores da linha lacaniana de pensamento relatam que a transmissão de conhecimento sobre uma experiência não basta para que o sujeito a vivencie de fato. É apenas na relação com o outro, estabelecida pela linguagem, que se pode elaborar psicologicamente e sedimentar uma experiência particular ${ }^{(25)}$. Tal pensamento apresenta afinidade direta com a relação professor-aluno de canto, na qual a linguagem metafórica/simbólica ocupa lugar de destaque.

Neurocientistas explicam que a memorização e a padronização de movimentos complexos, como o andar ou o tocar um instrumento (ou os milimétricos ajustes musculares do canto), ficam armazenadas do lado direito do cérebro, e pertencem ao universo de informações localizadas na região inconsciente e irracional do ser humano ${ }^{(26,27)}$. Nesse sentido, pode ser que as imagens se constituam numa poderosa ferramenta didática à absorção tanto de conceitos musicais quanto à fixação e automação de movimentos complexos necessários ao refinamento da técnica vocal.

Por fim, neurocientistas cognitivos esclarecem que as emoções causam respostas físicas não somente no cérebro, mas no corpo todo, e reforçam a ideia de que a dicotomia cartesiana entre corpo e mente não corresponde ao real processo cognitivo do ser humano. O corpo todo é necessário para explicar o pensamento, e o conceito de inteligência é o resultado de capacidades cognitivas que se interagem, inclusive daquelas não intelectivas ${ }^{(28)}$.

A imagem poderia ser, nesse contexto, um elo importante entre o aspecto subjetivo e o objetivo da inteligência, potencializando o aprendizado artístico assim como o técnico.

\section{CONCLUSÃO}

A maioria dos professores investigados utiliza o jargão 
metafórico conhecido no meio musical como "imagens" em seu processo de ensino. Os dados colhidos evidenciam que as imagens são consideradas por esses sujeitos como ferramenta para comunicar ao aluno tópicos pouco concretos ou objetivos relacionados ao canto e para estimular a aquisição de sensações proprioceptivas.

A maior parte da amostra utiliza imagens porque considera que explicações objetivas do ponto de vista fisiológico são de difícil compreensão, e que instruções musculares são de difícil execução.

Os resultados indicam que, ao não distinguir os objetivos musculares dos objetivos musicais e proprioceptivos das imagens, o professor de canto pode não estar plenamente consciente dos ajustes fisiológicos envolvidos em seu trabalho. Ao mesmo tempo, os depoimentos evidenciam que separar o processo fisiológico de produção da voz do processo subjetivo da criação artística pode não ser o caminho mais produtivo para o desenvolvimento da voz cantada.

O cruzamento entre os dados dessa pesquisa e a literatura pertinente ao tema mostra que é provável que as imagens estabeleçam uma conexão entre o universo técnico do canto e a imaginação criativa e o fazer artístico do cantor.

\begin{abstract}
Purpose: To verify whether singing teachers of different music styles use metaphoric expressions ("imagery") as didactic tools to teach vocal resonance, whether there is a desired physiological correspondence for each metaphor, and the reasons to use this kind of expression. Methods: The subjects were 20 singing teachers with at least five years of professional experience teaching one of four different musical styles (five teachers of each style). They answered questions based on other studies in the area, regarding their teaching experience and their use of metaphoric expressions. The teachers that confirmed using imagery to teach vocal resonance were asked to describe three examples currently used, and to explain its physiological and musical goals. The interviews were digitally recorded, fully transcribed, and posteriorly analyzed and classified. Results: From the teachers interviewed, 90\% used imagery for pedagogical reasons, concerning either technical or musical matters; $88.8 \%$ of the teachers that affirmed to use metaphoric expression with physiological purposes were not able to describe precisely what they were trying to achieve, or mixed physiological goals with musical and proprioceptive objectives. Conclusion: Most of the singing teachers that participated in this study used metaphors as didactic tools, believing that this kind of imagery stimulates proprioception and musicality, and that instruction through physiological language is excessively complex. This finding might suggest that these professionals tend not to isolate the physiological process of voice production from the subjective process of artistic creation.
\end{abstract}

Keywords: Voice; Voice quality; Voice training; Phonation; Proprioception; Esthetics

\section{REFERÊNCIAS}

1. Barnes-Burroughs K, Lan WY, Edwards E, Archambeault N. Current attitudes toward voice studio teaching technology: a bicoastal survey of classical singing pedagogues. J Voice. 2008;22(5):590-602.

2. Weekly EM, LoVetri JL. Contemporary Commercial Music (CCM) survey: who's teaching what in nonclassical music. J Voice. 2003;17(2):207-15.

3. Vurma A, Ross J. The perception of "forward" and "backward placement" of the singing voice. Logoped Phoniatr Vocol. 2003;28(1):1928.

4. Vurma A. Voice quality and pitch in singing: some aspects of perception and production [dissertation]. Tallin: Estonian Academy of Music and Theatre Dissertations; 2007.

5. Clements JF. The use of imagery in teaching voice to the twenty-first century student [dissertation]. Florida State University College of Music; 2008

6. Vurma A, Ross J. Where is a singer voice if it is placed "forward"? J Voice. 2002;16(3):383-91.

7. Miller R. The structure of singing: system and art in vocal technique. Nova Iorque: G. Schirmer; 1986.

8. Weekly EM, Lovetri JL. Follow-up Contemporary Commercial Music (CCM) Survey: who's teaching what in nonclassical music. J Voice. 2009;23(3):367-75.

9. Glaser S, Fonterrada M. Músico-professor: uma questão complexa. Musica Hodie. 2007;7(1):27-49.

10. Felix SM. O ensino de canto no Brasil: uma visão histórica e uma reflexão aplicada ao ensino de canto no Brasil [dissertação]. Rio de Janeiro: Escola de Música da Universidade Federal do Rio de Janeiro; 1997.
11. Nogueira-Martins MCF, Bogus CM. Considerações sobre a metodologia qualitativa como recurso para o estudo das ações de humanização em saúde. Saude Soc: 2004;13(3):44-57.

12. Riggs S. Singing for the stars: a complete program for training your voice. Van Nuys, CA: Alfred Publishing; 1985.

13. Werbeck-Svärdström V. A escola do desvendar da voz: um caminho para a redenção na arte do canto. 2a ed. São Paulo: Antroposófica; 2004.

14. Zampieri SA, Behlau M, Brasil OOC. Análise de cantores de baile em estilo de canto popular e lírico: perceptivo-auditiva, acústica e da configuração laríngea. Rev Bras Otorrinolaringol. 2002;68(3):378-86.

15. Austin SF. Movement of the velum during speech and singing in classically trained singers. J Voice.1997;11(2):212-21.

16. Sundberg J. Phonatory vibrations in singers: a critical review. Music Perception. 1992;9(3):361-82.

17. Erickson ML, Perry S, Handel S. Discrimination functions: can they be used to classify singing voices? J Voice. 2001;15(4):492-502.

18. Lima MFB, Camargo ZA, Ferreira, LP, Madureira S. Qualidade vocal e formantes das vogais de falantes adultos da cidade de João Pessoa. Rev CEFAC. 2007;9(1):99-109.

19. Araújo S, Fuks L, Amaral U, Pinto YWF. Diálogos entre a acústica musical, a fisiologia da voz e a etnomusicologia: um estudo de caso de estilos vocais no samba carioca. Per Musi (Belo Horizonte). 2003;7:52-67.

20. Iwarsson J, Thomasson M, Sundberg J. Effects of lung volume on glottal voice source. J Voice.1998;12(4):424-33.

21. Hirano M, Vennard W, Ohala J. Regulation of register, pitch and intensity of voice: An electromyographic investigation of intrinsic laryngeal muscles. Folia Phoniatr (Basel). 1970 22(1):1-20. 
22. Carlsson-Berndtsson G, Sundberg J. Formant frequency tuning in singing. J Voice. 1992;6(3):256-260.

23. Sundberg J, Gramming P, Lovetri J. Comparisons of pharynx, source, formant and pressure characteristics in operatic and musical theatre singing. J Voice. 1993;7(4):301-10.

24. Gambini R. Sonhos na escola. In: Scoz B, organizador. (Por) uma educação com alma: a objetividade e a subjetividade nos processos de ensino/aprendizagem. Petrópolis: Vozes; 2000. p.103-60.

25. Checchia MA. Considerações iniciais sobre lógica e teoria lacaniana. Psicologia USP. 2004;15(1/2):321-38.
26. Sacks O. Alucinações musicais: relatos sobre a música e o cérebro. São Paulo: Companhia das Letras; 2007.

27. Classen J, Liepert J, Wise SP, Hallett M, Cohen LG. Rapid plasticity of human cortical movement representation induced by practice. J Neurophysiol. 1998;79(2):1117-23.

28. Barros CE, Carvalho MIM, Gonçalves VMG, Ciasca SM, Assis OZM. $\mathrm{O}$ organismo como referência fundamental para a compreensão do desenvolvimento cognitivo. Rev Neuroci. 2004;12(4):212-6. 